\title{
Skin Cancer Detection using Image Processing Technique
}

\author{
K.Harish Reddy, T.J.Nagalakshmi
}

\begin{abstract}
A skin homes like pores and skin dryness increase and unfavorably inclined warning signs for instance scratching kind of difficulty relationship with skin floor profile is talked about in the proposed proposition work. In the current situation, the pores and skin pix are examined in recurrence space. Be that as it may, it is considered that the skin shading in surface photographs does no longer fluctuate over a vast range. The dark shading profile of the skin surface may also give life thought regarding the pores and skin affectability and is some other growing pores and skin surface examination device. In the proposed work, skin dim shading profile has been taken as the data parameter so as to discover the pores and skin profile.To manage this inconvenience shoot there is a prerequisite to create PC supported indicative frameworks to motivate the regular population for the early location of the melanoma. The preliminary step contains skin damage division. The following simply improve is to cast off the spotlight and example examination strategies to make an analysis of the influenced region. This paper gives a sketch to manage the division, identification and characterization of the pores and skin disease and the influenced zone utilising pass breed picture handling strategies.
\end{abstract}

Keywords- Skin cancer, Asymmetry, Border, Color, Diameter.

\section{I.INTRODUCTION}

An accumulation of irregular cells in our physique is title as malignancy. In men malignant growth will begin anyplace within the physique and unfold into the encircling tissues that comprises trillions of cells. Ordinarily, human cellular telephone enhances and separation to body new cells as per the requirement of the physique and it alternates man or feminine to individual. At the element once malignancy starts off evolved to make within the physique the approach of enterprise of the latest mobile stops and therefore the phone seems to be bigger what is a lot of, a lot of and a lot of additional traditional and every completely different cell form that isn't needed. That further smart phone develops typically and observed as tumors. Cancer tumors as harmful. This suggests they'll improve and unfold into connected tissues. In speedy infections during which abnormal cells isolate wildly and obliterate physique tissue taking place tumors The pores and skin is that the largest organ of the body. The pores and skin secures North American country from organisms and from the distinctive hurtful materials. Skin has 3 layers, 2 strata the external layer of the skin and makes our pores and skin tone. Stratum

\footnotetext{
Revised Manuscript Received on August 14, 2019.

K.Harish reddy, Student, Department of ECE, Saveetha Institute Of Medical and Science,SIMATS, Chennai, Tsmilnadu, India.

Ms.T.J.Nagalakshmi, Assistant professor, Department of ECE, Saveetha institute of medical and science,SIMATS, Chennai, Tsmilnadu,
} India. it's to a lower place the stratum and consists of utmost animal tissue and sweat organs.

Frequently pores and pores and skin malignant extend creates on pores and pores and skin delivered to the sun but it will likewise show abreast of zones that isn't continuously sun uncovered. There are 3 styles of skin malignant enlarge Basel mobile phone sickness, epithelial cell illness and malignant melanoma tumors. Basel cellular telephone begins in Basel layer of the skin. It happens on the face. Squamous cellular telephone it starts off evolved in squamous. Cell phone and for the most phase discovered in dull individuals. Melanoma-it starts in Malicious layer and show up at mouth and eyes. The preliminary two is no longer all that normal and do not spread all at once be that as it may, the 0.33 pores and pores, and skin sickness unfold in all respects hastily over the body. In the event that it is not decided in establishing times, it is determined as stepped by way of step risky. It all more in many situations located in woman contrast with men. Most generally guys have this sickness at their once more and aides undergo it on their legs. Melanoma is a malignant boom that starts off evolved in melanocytic. Melanoma well on the way to unfold to one of form portions of the body the place it is hard to deal with and fix. Science and innovation assists to manipulate these kinds of pores and skin maladies. A standout amongst the most extensively recognized method which is typically utilizing all over for the identification, and the affiliation of this illness is photograph handling. The pores and skin floor is the presence of the pores and skin smooth surface. To the highlights of this surface, numerous variables are happening, for example, food plan and hydration, measure of collagen and hormones, and, obviously, healthy skin. A non-stop limit in pores and skin is in addition, superimposed by way of age. As pores and skin ages, it winds up extra slim and all the greater effectively harmed, with this seems to be of wrinkles. The decay is too joined with the resource of an obscuring of pores and pores, and skin shading for an over retention of the frequent shading color, melanin, stop most telephone layer in skin. The pores and skin ground likewise relies upon its physique area. On account of photograph preparing, we favor to consider the way that flooring seem to be is altering with picture recording parameters, that are camera, brightening also, path of view, an issue fundamental to any genuine surface. The challenge to have a quantitative assessment of the pores and skin highlights are very unpredictable, as in each and each one of the conditions the place image examination ought to be related to surface with

Published By:

Blue Eyes Intelligence Engineering \& Sciences Publication

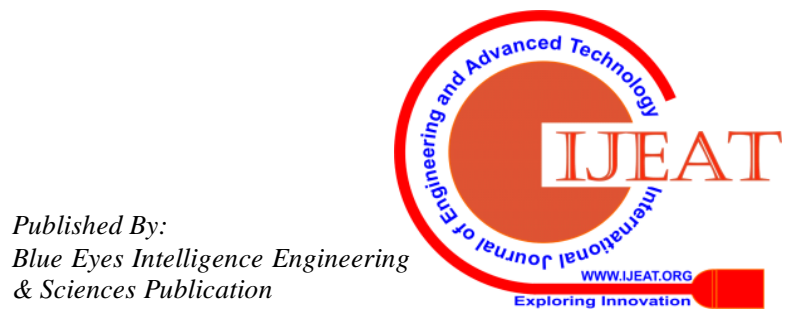


unpredictable non- intermittent examples. In the computerized picture handling, a few methods have been created to represent snap shots, and signify measurable separations amongst them, with the count on to choose whether, in a lot of numerous pictures, there exist some which are shut to any self-assertive photo lately experienced. The surface's expiration can be gotten by way of choosing a lot of traits, the flooring highlights, which characterize the spatial affiliation of the picture.

\section{METHODOLOGY}

A factual method for searching at floor that considers the spatial relationship of pixels is the Darkish dimension coevent framework (GLCM), in any different case referred to as the Darkish dimension spatial reliance lattice. The GLCM capacities describe the surface of a photo by way of the use of figuring how frequently combines of pixel with specific characteristics, and in a predefined spatial relationship occur in a picture, making a GLCM, and later on isolating factual measures from this matrix. He proposed technique of melanoma area and conclusion is appeared.

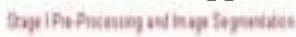

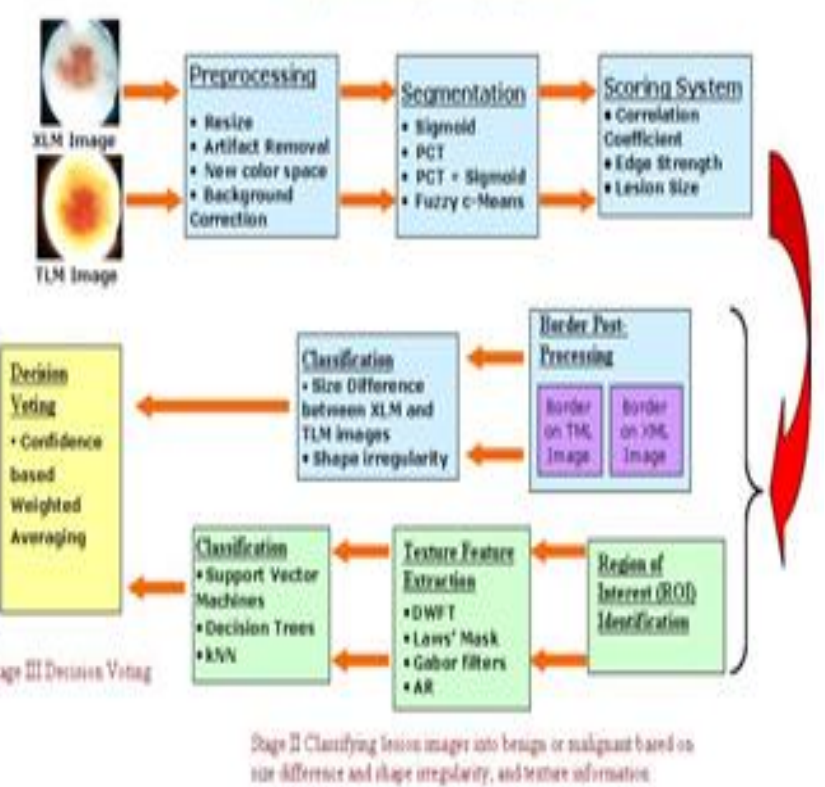

Fig 1: flow chart

The technique utilizes the following advances: Image securing from computerized camera, Rehandling includes clamor expulsion, highlight extraction both factual and endoscopic, highlight choice, ascertaining TDS, order utilizing neural system and afterward assessment. Image Acquisition: Picture procurement is characterized as the way toward catching or recovering a picture from a camera, So, it very well may be passed through different procedures need to happen later.

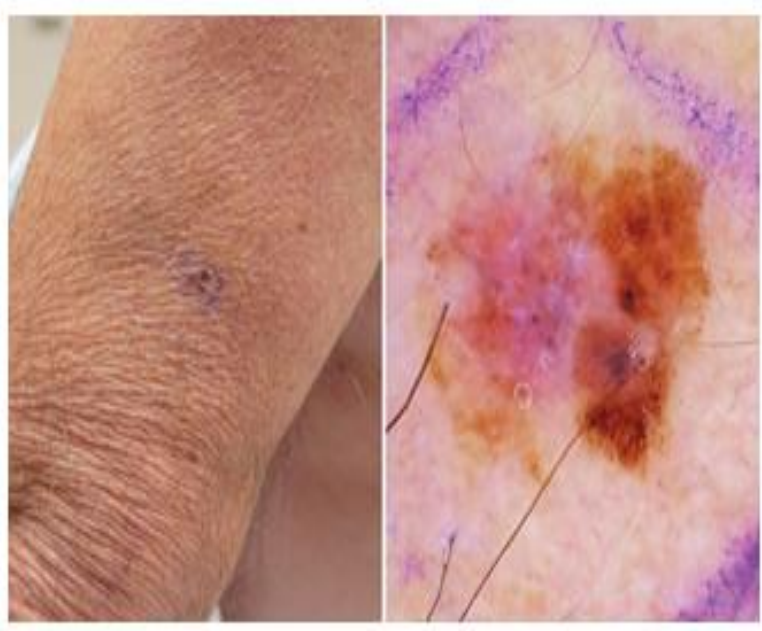

Fig 2: skin cancer starting stage

Picture procurement in picture handling is the initial phase in the work process grouping since, without a picture, no further procedure is conceivable. Image Rehandling: The rehandling is a change of the picture information that evacuates undesirable twists or improves a few hats it underpins highlight grouping with precision. From that point onward, pictures are changed over from RGB (Red, Green, and Blue) to dark dimension where the highlights depend on dim dimension co-event grid (GLCM). Image Segmentation: Division of picture manages the way toward dividing an advanced picture into numerous portions (sets of various pixels) the objective of this procedure is to rearrange or potentially change the portrayal of a picture into something that is increasingly significant and less demanding to analyze.

\section{EXISTING SYSTEM}

\section{Image processing:}

Picture rehandling earlier than examination of any photo set can happen; preprocessing ought to be performed on every one of the pictures. This technique is connected to ensure that each one of the snap shots are predictable in desired trademark. When working with Dermatoscopy pictures, rehandling can cover number of highlights like: image enlightenment evening out, shading ranged standardization, image scale fitting, or picture desires standardization. This can be challenged to characterize essentials and techniques connected in post handling. A case of rudimentary activity, for example, photo standardization is the goals coordinating. Expecting that the photo estimate in pixels is given, and all photographs are in a similar extent (for instance, viewpoint share of 4:3), it is something however difficult to discover the photographs of the littlest desires and after that scale the greater pictures to coordinate the measure of the littlest one. This exercise allows figuring the highlights like sore measurements, damage fringe length. 

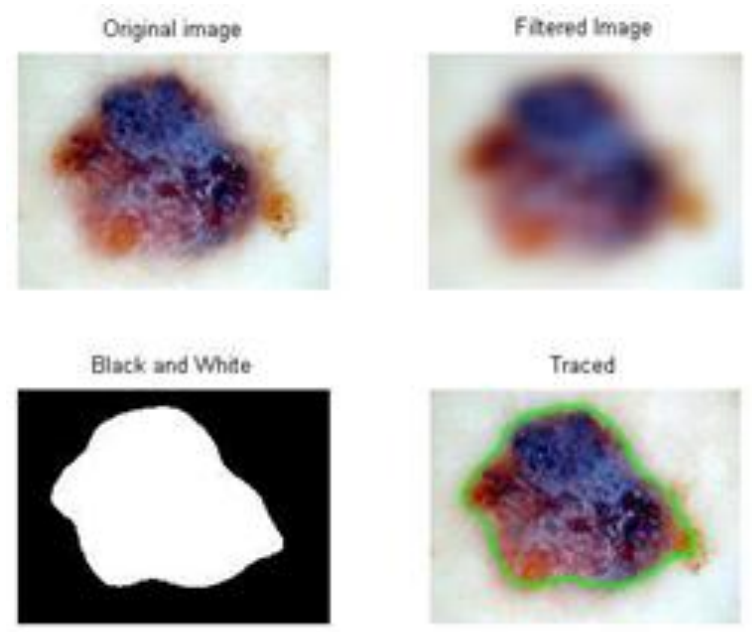

Fig3: identification using image processing

It is plausible to standardize extraordinary parameters like shading palette standardization, shading immersion standardization, standardization of shading parts, etc. Common mission in preprocessing is shading factors standardization, known as the histogram balance. Picture histogram is the dispersion of coloration esteems in the middle of outrageous coloration utilized in the palette. Expecting the circumstance where the most awesome features of the gray scale photograph is no longer white and the darkest focuses are no longer dark, performing histogram adjustment will redistribute every one of the hues of the picture such that most amazing spot of the treated picture will be shading and the darkest locales of the photograph will go towards turning into black.

\section{PROPOSED SYSTEM}

In this way, early, rapid and compelling recognition of skin disorder is central significance. Whenever recognized at a commencing time, skin has one of the most noteworthy restore rates, and the most cases, the treatment is very straightforward, and includes extraction of the injury. Besides, at a commencing time, pores and skin malignancy is notably sensible to treat, whilst at a late stage, hazardous sores basically end result in close lethal effects and fantastically mind-boggling expenses related with the necessary medicines. All matters considered, the most perfect approach to bring down the risk of melanoma is to restrain the presentation to strong daytime and other wellspring of Ultraviolet light. Deal with all the vital estimates, for example, making sure skin with apparel, carrying a cap, utilizing sunscreen, last in the coloration and so forth . Additionally, dependably remain alert about skin and do month to month skin-self tests to lessen the opportunity of getting any skin sickness which is a hazard to human life.

\section{DISCUSSION \& RESULTS}

Division is the initial phase in early discovery of skin malignancy. To dissect, it is important to precisely find and disengage the sores. In this three unsupervised division technique for skin sores have been examined. In the Ostu's strategy, it has appeared best division results among the three techniques. It is completely unsupervised that does not require any difference in parameter for various skin sores.

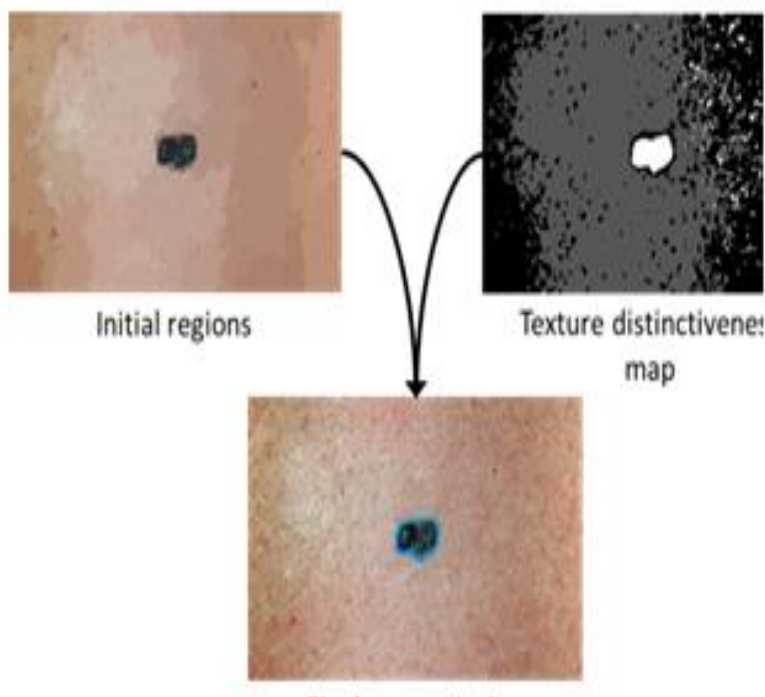

Final segmentation

FIG 4 :Skin cancer identification process

The second one, the slope vector stream gets in dynamic form to limit concavities, notwithstanding when the commotion is available. The execution speed is extremely moderate and that is the disadvantage. To merge to objects long time is taken. This technique isn't completely unsupervised. For various skin sores changing parameters is required. Then again, utilizing shading based division; it is conceivable to lessen the computational expense

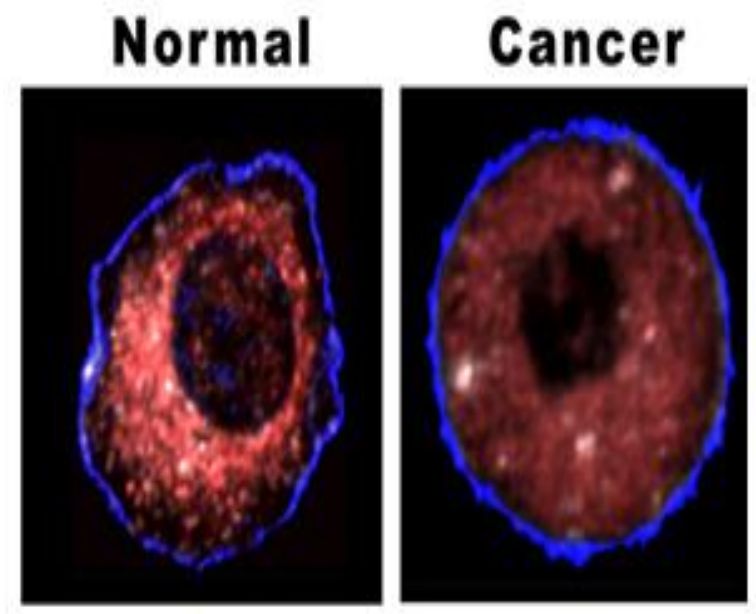

Fig 5: output image

retaining a strategic distance from spotlight figuring for each pixel in the picture. In spite of the fact that the shading isn't always as frequently as viable utilized for photograph division, it offers a high discriminative depth of areas present in the picture. This kind of photograph division might be utilized for mapping the adjustment in land use land unfold assumed control over transient duration when all is stated in achieved but not specifically. Highlight extraction is considered as the most primary state of theart skin malignant boom screening framework. 


\section{PROS AND CONS}

Skin afflictions are visit ailments to every person and diverse sorts of maladies are twisting up incredibly visit. You understand that these infections are amazingly damaging, especially if not controlled at a starting period. Skin diseases not simply hurt the skin. It can largy influence a person's consistently life, pummel conviction of an individual, hang their improvement, and swing to hopelessness. A portion of the time, various people endeavor to treat these sensitivities by using their own special treatment. Nevertheless, on the off chance that these strategies are not appropriate for that sort of skin ailment, at that point it would make it continuously terrible. Skin sicknesses can without a lot of a stretch trade from human to human so there is a need to control it their fundamental stage to deflect itfrom spreading. This paper shows a use of a skinmaladies investigation structure which urges customer to distinguish human skin diseases and gives therapeutic drugs promising. Thus, customer should exchange a sickness impacted skin picture to our system to the symptoms of the skin.

\section{CONCLUSION}

The last yield given by the framework will assist the dermatologist with detecting the sore and its sort, in like manner with his insight he will analyze the patient to reach a last inference whether it very well may be worked or not or some other method to fix it for example utilizing drugs or salves, and so forth. Skin malignant growth recognition System will assist Dermatologist with diagnosing melanoma in beginning times. The extension is that the framework can be actualized in the independent application. The framework can be increasingly dependable and vigorous. The framework may give the Encryption of information and verification for the clients so that there is no unapproved access of the information of the patient, in such a case that there is unapproved get to is performed on the information then the information uprightness might be lost.

\section{REFERENCES}

1. Nilkamal S. Ramteke and Shweta V. Jain, ABCD rule based automatic computer-aided skin cancer detection using MATLAB, Nilkamal $S$ Ramteke et al, Int.J.Computer Technology and Applications, Vol 4 (4), 691-697.

2. Md.Amran Hossen Bhuiyan, Ibrahim Azad, Md.Kamal Uddin, Image Processing for Skin Cancer Features Extraction, International Journal of Scientific and Engineering Research Volume 4, Issue 2, February-2013 ISSN 2229-5518

3. Maciej Ogorzaek, Leszek Nowak, Grzegorz Surowka and Ana Alekseenko, Modern Techniques for ComputerAided Melanoma Diagnosis, Jagiellonian University Faculty of Physics, Astronomy and Applied Computer Science Jagiellonian University Dermatology Clinic, Collegium Medicum Poland.

4. Leszek A. Nowak, Maciej J. Ogorzaek, Marcin P. Pawowski, Texture Analysis for Dermoscopic Image Processing, Faculty of Physics, Astronomy and Applied Computer Science Jagiellonian University Krakw, Poland.

5. G. GRAMMATIKOPOULOS, A. HATZIGAIDAS, A. PAPASTERGIOU, P. LAZARIDIS, Z. ZAHARIS, D.
KAMPITAKI, G. TRYFON, Automated Malignant Melanoma Detection Using MATLAB, Proceedings of the 5th WSEAS Int. Conf. on DATA NETWORKS, COMMUNICATIONS and COMPUTERS, Bucharest, Romania, October 16-17, 2006.

6. A.Aswini, E.Cirimala, R.Ezhilarasi, M.Jayapratha, NonInvasive Screening and Discrimination of Skin Images For Early Melanoma Detection, International Journal of scientific research and management (IJSRM), Volume, 2, Issue, 4, Pages 781- 786, 2013

7. Nisha Oommachen, Vismi V, Soumya S, Jeena C D. Melanoma Skin Cancer Detection Based on Skin Lesions Characterization, IOSR Journal of Engineering (IOSRJEN) e-ISSN: 2250-3021, p-ISSN: 2278-8719 Vol. 3, Issue 2 (Feb. 2013), V1, PP 52-59.

8. Arati P. Chavan D. K. Kamat Dr. P. M. Patil, CLASSIFICATION OF SKIN CANCERS USING IMAGE PROCESSING, International Journal of Advance Research in Electronics, Electrical Computer Science Applications of Engineering Technology Volume 2, Issue 3, June 2014, PP 378-384. 